
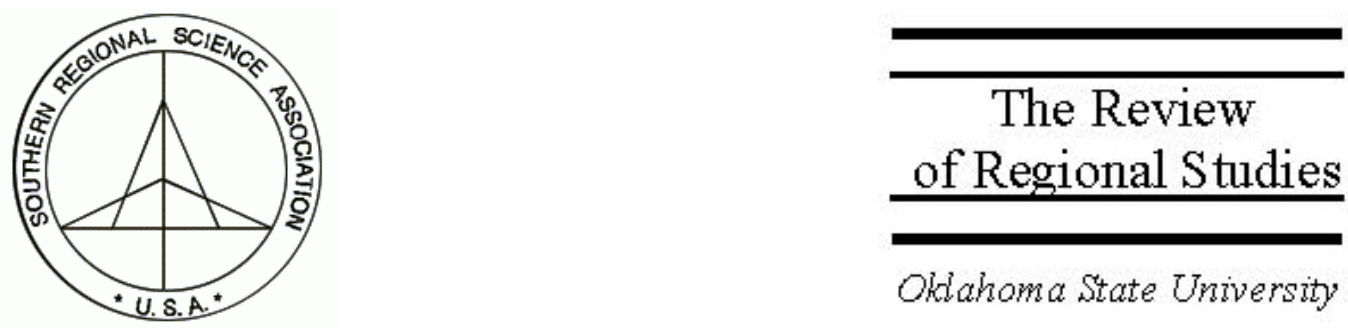

\title{
Wages and Industrial Clusters in Rio Grande do Sul (Brazil)
}

\author{
Leonardo Monteiro Monasterio \\ Department of Geography and Economics, Federal University of Pelotas \\ Rua Coronel Alberto Rosa 154, Pelotas, RS, 96010-770, Brazil. \\ Visiting Research Fellow, Institute for the Study of the Americas, University of London, \\ e-mail: leonardo.monasterio@gmail.com
}

\begin{abstract}
The purpose of this paper is to test whether the New Economic Geography hypothesis concerning the existence of a spatial wage structure applies to the state of Rio Grande do Sul, Brazil. The first part of the study applies several spatial analysis techniques in order to locate industrial clusters and calculate the market potential of the municipalities studied. The second part uses this information together with demographic data to run wage regressions aimed at capturing the effects of agglomeration and urban economies on individual wages. The results do not falsify the hypothesis that nominal wages, using the proper controls, are higher in municipalities with higher market potential and lower in the economically disadvantaged hinterland of the state.
\end{abstract}

Keywords: Spatial wage structure; New Economic Geography; Rio Grande do Sul

JEL classification: $R 12 ; R 14$

This research was supported by the Brazilian Science Council (CNPq). Otávio Damé and Martin D. Brauch provided excellent research assistance. The author is grateful to Sergio Rey, Mark Janikas, Juan Carlos Duque, and the other members of the Regional Analysis Laboratory of San Diego State University (REGAL/SDSU) for their lessons and support. The author would like to thank the referees and Edson P. Domingues for perceptive comments. The usual disclaimer applies. 


\section{INTRODUCTION}

The purpose of this paper is to test whether a spatial wage structure exists in the state of Rio Grande do Sul, Brazil. Inspired by the New Economic Geography approach (henceforth referred to as NEG), the study aims to measure the effects of locational factors on wages. The state of Rio Grande do Sul occupies an area of approximately $300,000 \mathrm{~km}^{2}$ (roughly the size of Italy) and has around 10 million inhabitants. Its socioeconomic indicators are relatively high in comparison to Brazil as a whole. ${ }^{1}$ The service sector is the main economic activity of the state (44 percent of its GDP), followed by manufacturing (41 percent) and agriculture (15 percent). However, there are huge regional disparities. The economic history of the different regions has produced a range of features that even today shape public concerns and policies. Reduction of the regional inequalities within the state is usually at the top of the political agenda. Nevertheless, about 61 percent of the state's industrial production is concentrated in the regions around the axis Porto Alegre-Caxias do Sul (Fundação de Economia e Estatística 2006).

There is a wide range of academic literature on regional issues in Rio Grande do Sul. ${ }^{2}$ Despite the quality of this literature, modern methods of spatial analysis are almost unknown among local researchers, and there are few studies on quantitative geographical methods applied to economic issues. In recent times, there have been interesting longterm studies on the quantitative indicators of industrial concentration (Lautert 2002) but no explicit spatial analyses. Among the few studies that apply exploratory analysis of spatial data (ESDA) techniques to the economic issues of Rio Grande do Sul is the recent paper by Ruiz and Domingues (2005).

In the first part of the study, several spatial analysis techniques are used in order to identify the industrialized and high market potential areas of the state. Spatial smoothing, ESDA, and implicit spatially constrained clustering techniques are applied to the 467 municipalities of Rio Grande do Sul.

This information is relevant to the second part of the study, which uses census data to estimate the impact of agglomeration economies on individual wages across the population of the state. The specific purpose is to test the prediction of a spatial wage structure in line with NEG models (Krugman 1991; Hanson 1997, 1998, 2000). Is labor productivity (and hence the wages) of workers located near the core of the economy higher than on the periphery? In order to answer this, Section 2 gives the results of a Mincerian regression that includes the locational variables.

The basic source of data is the sample of the Demographic Census of 2000 (Instituto Brasileiro de Geografia e Estatística 2002). This dataset is considered one of the best

\footnotetext{
${ }^{1}$ The Appendix shows figures of the state, its main cities, and the Human Development Index of its municipalities.

${ }^{2}$ See Alonso, Benetti, and Bandeira (1994).
} 
available sources in Brazil. One of its main features is that it includes the "informal" sector of the economy, which is very important in Brazil because of the large number of workers that it employs. ${ }^{3}$ After selecting only individuals with the appropriate traits, the sample was reduced to about 55,000 manufacturing workers.

The results suggest that NEG predictions of a spatial wage pattern do indeed exist in Rio Grande do Sul. However, the conclusions of the study are to some extent preliminary, and the same database can generate new insights concerning regional issues within the state.

\section{SPATIAL INDUSTRIAL CLUSTERS IN RIO GRANDE DO SUL}

\subsection{Spatial Distribution of Manufacturing Employees}

Exploratory Spatial Data Analysis is the set of techniques used to describe spatial distribution, uncover patterns of spatial correlation or clusters, and identify outliers (Anselin 1998). This section will begin with very simple data visualization methods, and progressively more sophisticated techniques will then be applied. Figure 1 below depicts the map of distribution of raw manufacturing employment, and its participation in the total working population.

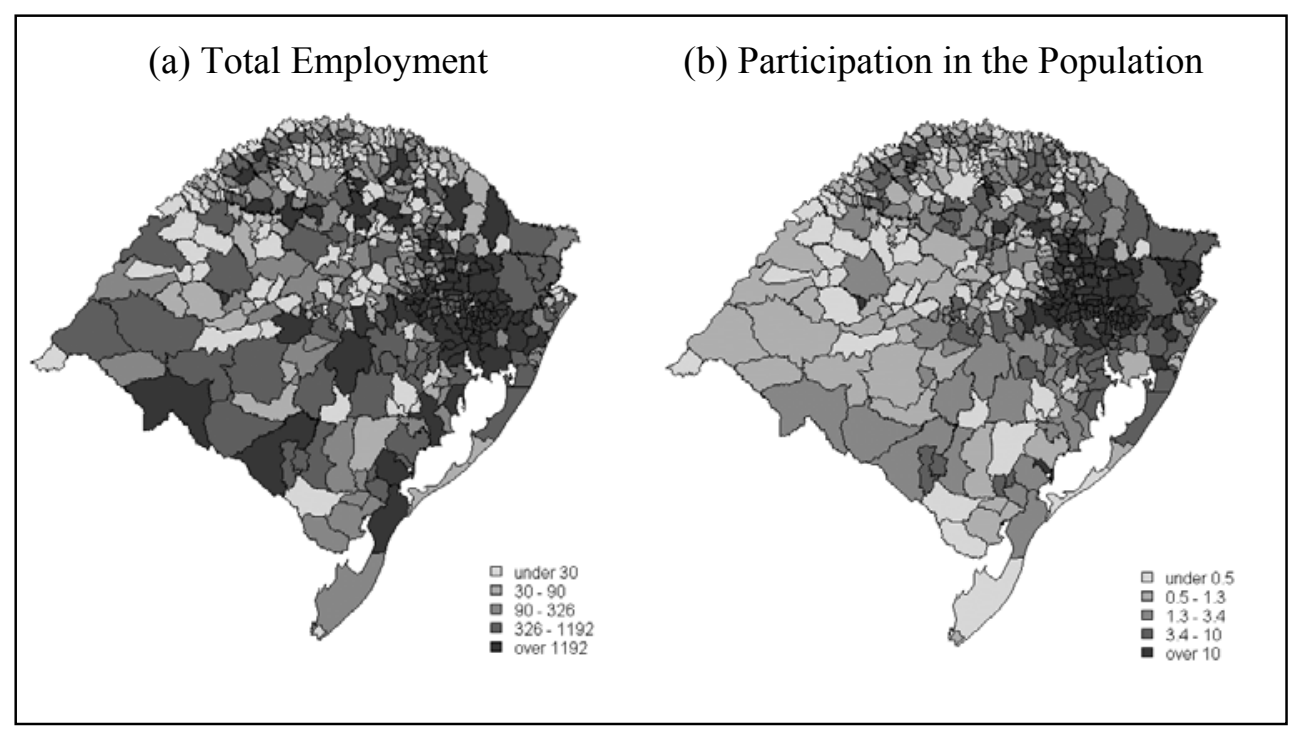

FIGURE 1. Industrial Employment in Rio Grande do Sul

\footnotetext{
${ }^{3}$ It has been suggested that 54 percent of the workforce in Brazil is employed in the informal sector of the economy (Gonzales et al. 2002).
} 
The raw data map creates an illusion that manufacturing employment is well distributed across space. The rate map, on the other hand, indicates that the northern part of the state seems more industrialized than the southern part. One of the problems of this data visualization is that the size of the population of municipalities is very diffused. The smallest has about 1,000 inhabitants, while Porto Alegre has more than 1.3 million. As is widely known, this fact makes the variance of the rate in the smallest municipalities higher than in the largest ones.

In order to reduce the heteroskedasticity of the data, a process of data smoothing is applied:

$$
\text { Smooth }_{i}=\frac{\sum_{j=1}^{R} W_{i, j} \text { Employment }_{i}}{\sum_{j=1}^{R} W_{i, j} \text { Population }_{i}},
$$

where Employment $t_{\mathrm{i}}$ is manufacturing employment in municipality $i, R$ is the total number of municipalities in Rio Grande do Sul (467), and $W$ is a contiguity matrix. $W$ was created with Geoda 0.95 (Anselin 2004) based on a distance band criterion. That is, the radius around each municipality centroid was drawn and every other centroid was counted as a neighbour. The chosen cut-off distance is the shortest one that creates a $W$ matrix without disconnected spatial units. This criterion results in a highly connected $W$ matrix, with an average of 69 neighbours per municipality. Another departure from the usual procedures is that the matrix is row standardized, but the values of the main diagonal are set equal to 1. This gives a more important role to the employment density in the unit during the spatial smoothing process. Figure 2 depicts the results. As expected, the results are smoother, and the data appear much more clustered than in Figure 1.

\subsection{Indicators of Global and Local Spatial Autocorrelation}

\subsubsection{Moran's-I}

Is manufacturing employment in the municipalities of Rio Grande do Sul spatially correlated with its neighbours? Moran's I will be used to evaluate the global autocorrelation of the data (O'Sullivan and Unwin 2003, p. 197):

$$
I=\frac{n}{\sum_{i=1}^{n}\left(y_{i}-\bar{y}\right)^{2}}\left(\frac{\sum_{i=1}^{n} \sum_{j=1}^{n} w_{i j}\left(y_{i}-\bar{y}\right)\left(y_{j}-\bar{y}\right)}{\sum_{i=1}^{n} \sum_{j=1}^{n} w_{i j}}\right),
$$




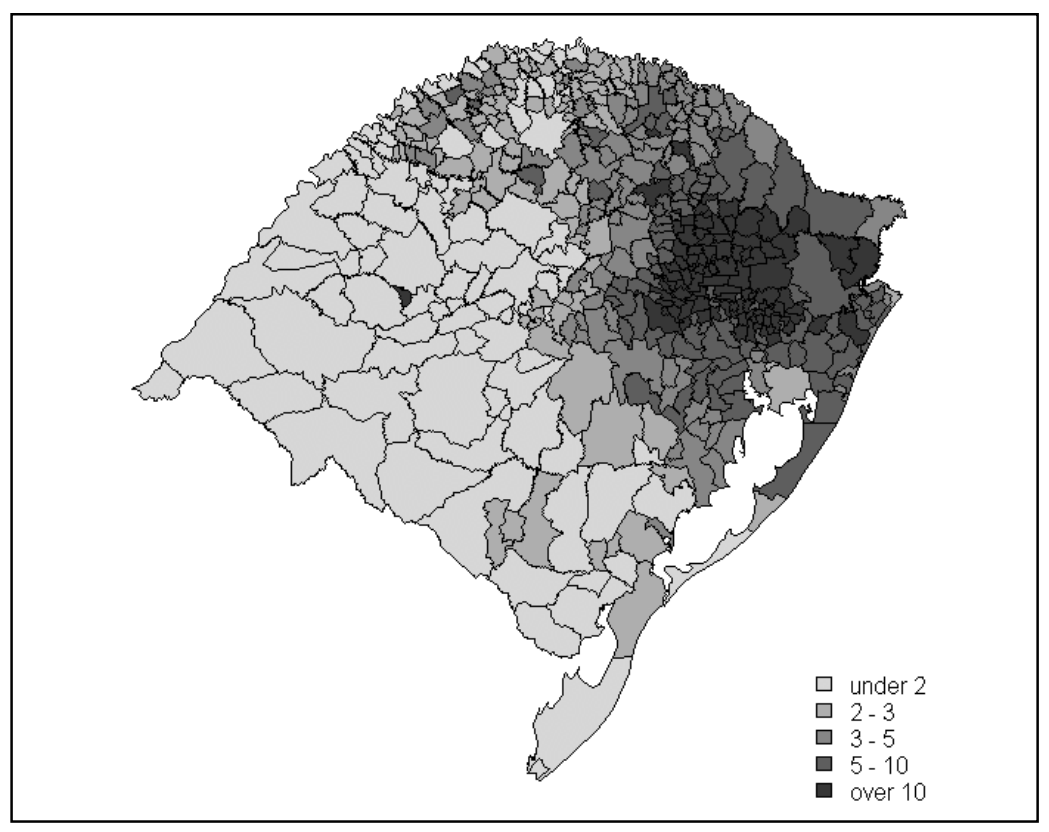

FIGURE 2. Smoothed Participation of Industrial Employment in the Population of Rio Grande do Sul - 2000

where $n=$ number of spatial units; $y_{i, j}=$ value of variable $y$ in $i$ or $j ; \bar{y}=$ mean of $y$; $w_{i j}=$ element $i, j$ from the $W$ matrix explained above.

Using SPDEP (Bivand 2006), the spatial econometrics package for $R$, the Moran I favor statistic was calculated as 0.33 and $\mathrm{H} 0$ (no spatial autocorrelation) was rejected in favor of $\mathrm{H} 1$ (positive autocorrelation). The Moran scatterplot provides additional information on the spatial structure of the data (Figure 3).

\subsubsection{Local Indicators of Spatial Association}

Moran's I statistic indicates global autocorrelation but is not able to indicate which areas are correlated with its neighbours. In order to solve this, local tests of autocorrelation were developed. Anselin (1995) established that a Local Indicator of Spatial Association (LISA) should have two properties: a) show which units have similar values around its neighbourhood; b) the sum of the individual LISA should be proportional to the global indicator of spatial autocorrelation. Local Moran's $I\left(I_{i}\right)$ has both properties (O’Sullivan and Unwin 2003, pp. 203-204):

$$
I_{i}=z_{i} \sum_{j \neq i}^{n} w_{i j}^{\prime} z_{j}
$$




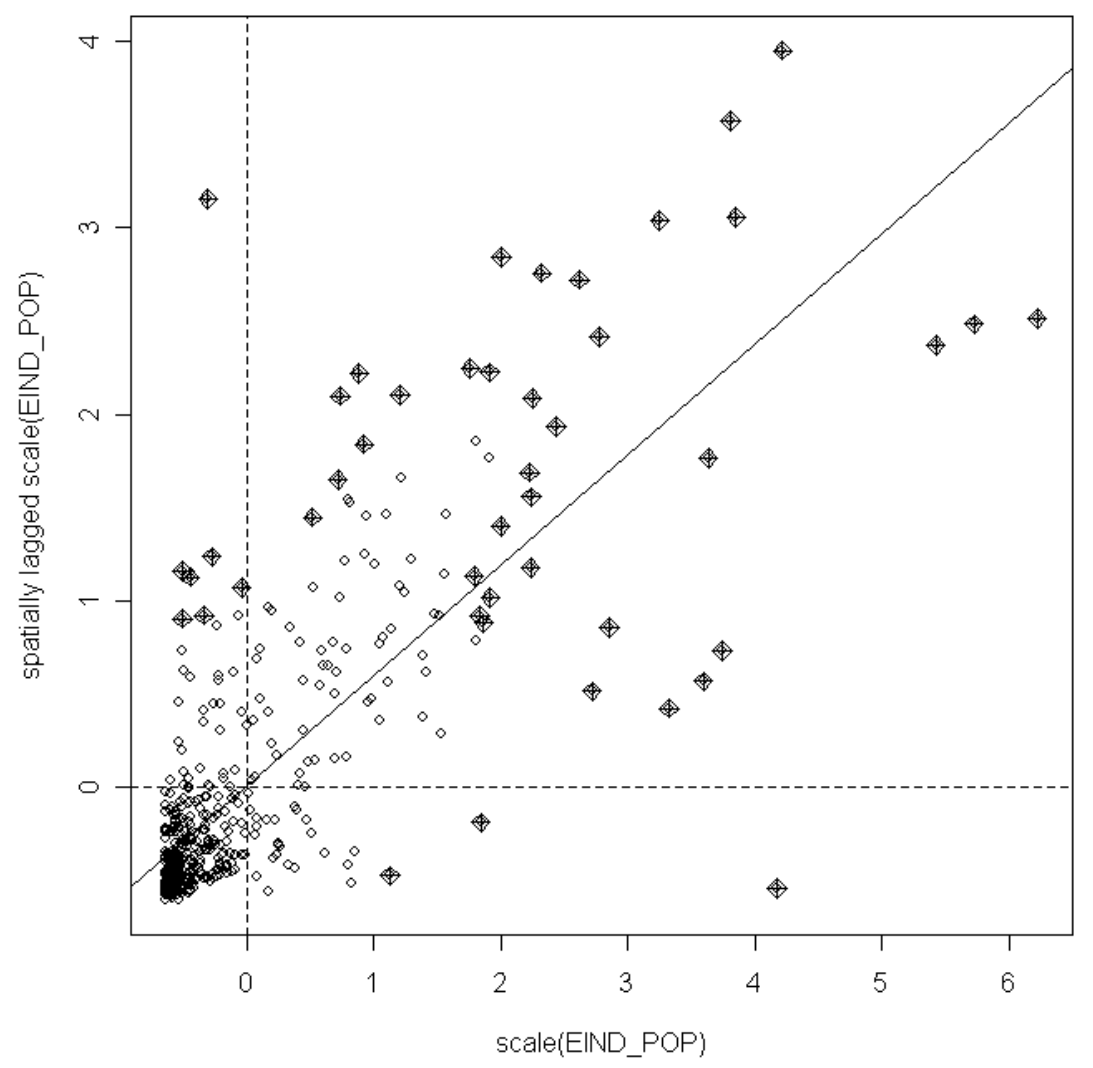

FIGURE 3. Moran Scatterplot for the Participation of Industrial Employment in the Population, Rio Grande Do Sul - 2000

$$
z_{i}=\frac{y_{i}-\bar{y}}{s}
$$

where $z$ are standardized values of $y$ and $w^{\prime}$ are normalized values of the $W$ matrix.

Intuitively, the value of a local Moran's I is equal to the value of the attribute on the place $i$ times the weighted average of its neighbours. Values of $I_{i}$ statistically higher than 0 suggest positive spatial autocorrelation, whilst those lower than 0 indicate negative spatial autocorrelation. In the present case, the $\mathrm{I}_{i}$ were calculated using the SPDEP package. ${ }^{4}$

${ }^{4}$ Geoda and ArcGis use permutations to generate the reference distribution. This produces different results not in the values of the $\mathrm{I}_{i}$, but in their statistical significance. 
In SPDEP, the values of Moran's I are compared to an analytical reference distribution. The map in Figure 4 highlights the areas of High-High clusters

\subsection{Market Potential}

The market potential of a region was defined by Harris (1954) as:

$$
M P_{i}=\sum_{j=1}^{R}\left(\frac{M_{j}}{D_{i j}}\right) .
$$

That is, $M P_{i}$, the market potential of $i$, is the sum of the demand in all places $j\left(M_{j}\right)$ weighted by the inverse of the distance $\left(D_{i j}\right)$. Previous regional studies of market potential were more interested in issues concerning manufacturing location. Not surprisingly, they found that manufacturing was concentrated near areas of high market potential (Brakman, Garretsen, and van Marrewijk 2003, p.36).

In this study, market potential will be calculated by using two techniques, the first of which reproduces Harris' (1954) proposal. In the second, the Euclidian distance to the

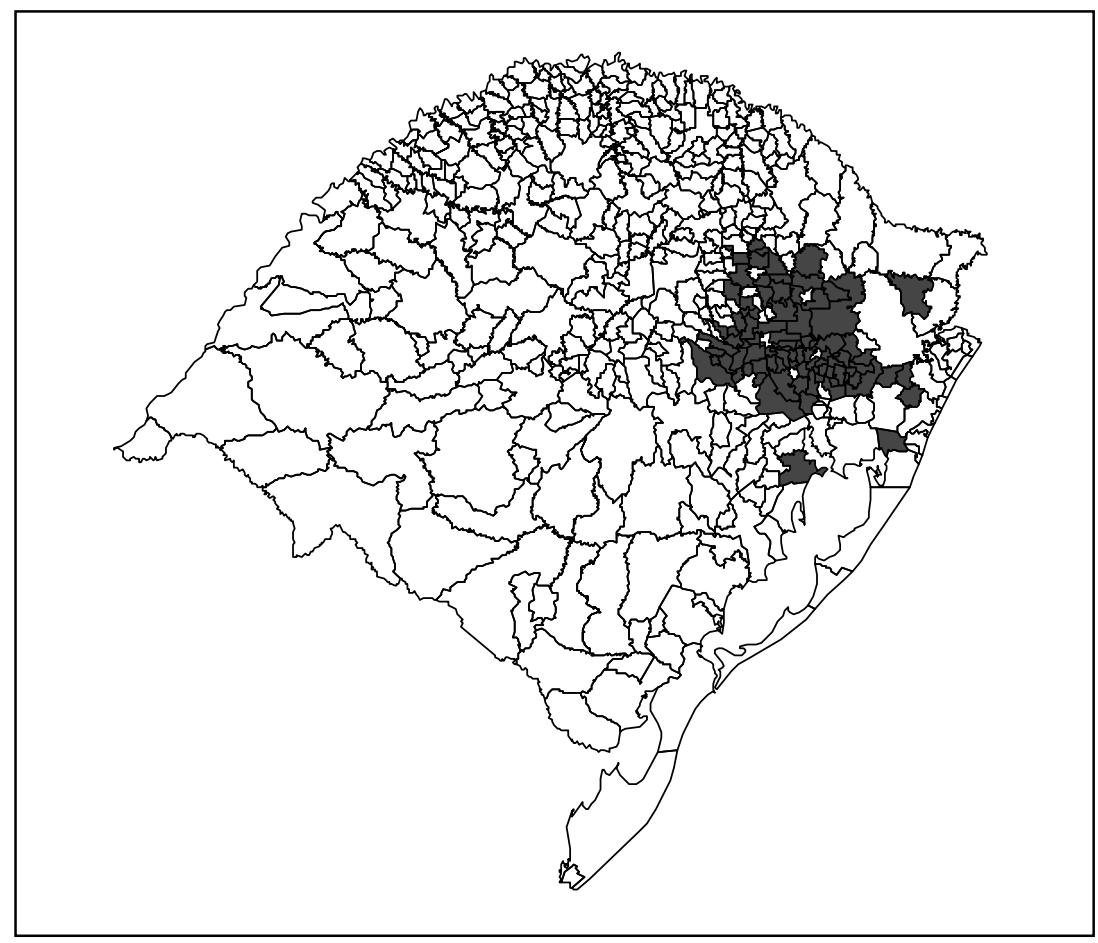

FIGURE 4. Moran's High-High Industrialization Clusters 
economic center of the state is estimated. Using GDP by municipality as the weighting variable, this center was calculated as follows:

$$
x_{m}=\frac{1}{n} \sum_{i=1}^{n}\left(x_{i} \frac{G D P_{i}}{\sum_{i=1}^{n} G D P_{i}}\right) \quad y_{m}=\frac{1}{n} \sum_{i=1}^{n}\left(y_{i} \frac{G D P_{i}}{\sum_{i=1}^{n} G D P_{i}}\right) \text {, }
$$

where $x_{i}$ and $y_{i}$ are the latitudes and longitudes of the centroids of each municipality. Using GDP data for 2001 (Fundação de Economia e Estatística 2003), the result is latitude 29.5923 South and longitude 52.0526 West. This position corresponds roughly to Santa Cruz do Sul, a town with a number of modern tobacco processing units.

Figure 5 represents the market potential. It is clear that the latter statistic provides a richer portrait of the economy of Rio Grande do Sul than the former. The industrial core, i.e., the axis Porto Alegre-Caxias do Sul, has a high market potential; but towns in the hinterland such as Santa Maria, Pelotas, and Rio Grande also show above average values.

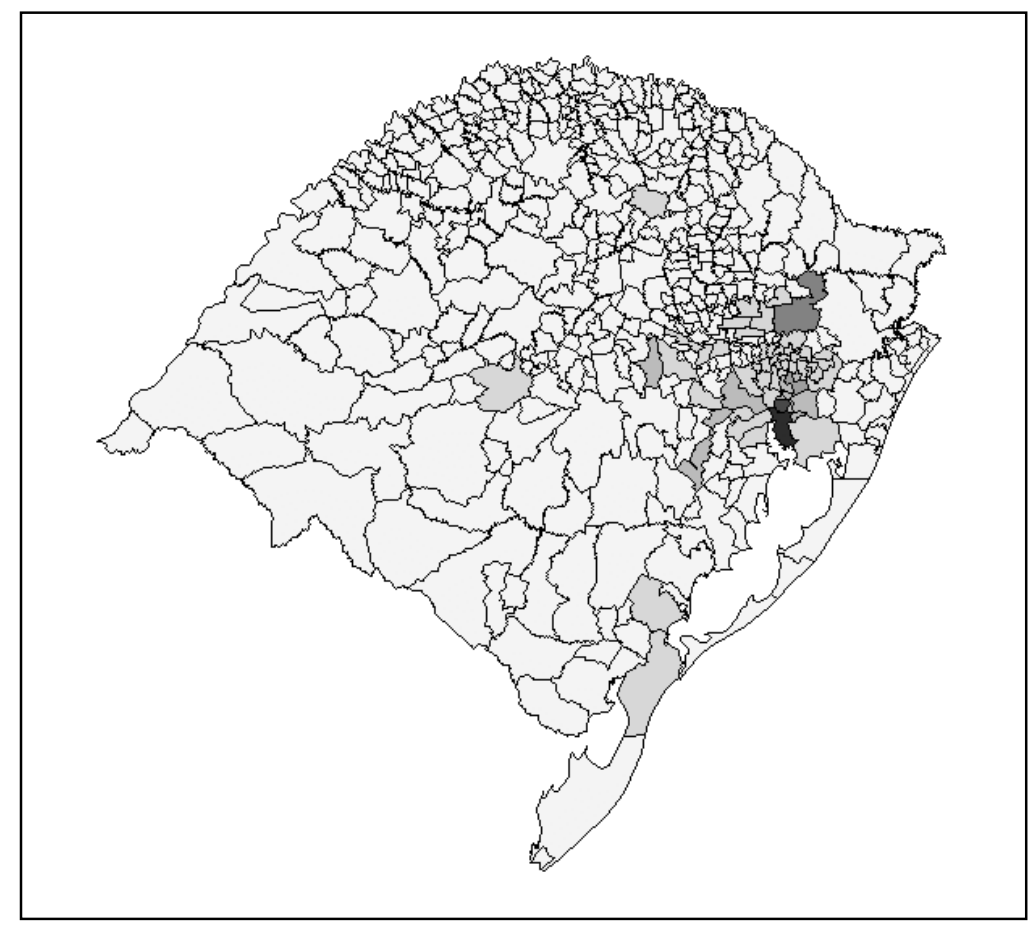

FIGURE 5. Market Potential 


\subsection{Implicit Spatially Constrained Clustering}

Implicit spatially constrained cluster analysis is a simple way of including spatial dimensions in clustering methods. The survey by Duque and Raúl-Ramos (2006) describes the various methods available, with their strong points and weaknesses. Although they are much more sophisticated than implicit spatially constrained clustering, this method generates a regionalization that is satisfactory for the purposes of this study.

In order to do it, the CLARA (clustering for large applications) algorithm in $\mathrm{R}$ applied (R Development Core Team 2006). This is a partitioning clustering method that is able to deal with very large datasets. The algorithm works roughly in two steps. First, it takes a sample of the data and applies a clustering method (PAM: partition around medoid) that creates $k$ medoids. Then each observation is assigned to its nearest medoid. The process is repeated several times (usually five), and the sum of the dissimilarities of the observations to their closest medoid is the algorithm's criteria to find the best solution.

In order to locate the industrial clusters, only four variables were used: latitude and longitude of the centroid of the municipality, market potential, and manufacturing employment in the working population (spatially smoothed) as calculated in previous sections of this paper. There is a variety of criteria for selecting the optimum number of clusters. For the purposes of this study, it was decided to consider the average size of the silhouette. In this case, the highest average size of the silhouette was reached with $k=3$. The resulting map is depicted in Figure 6.

There are three basic clusters. One includes the industrial core of the state, the socalled Porto Alegre-Caxias do Sul axis. The municipalities in this cluster are the most industrialized and/or are close to the most economically dynamic areas of the state, with high market potential. The two other clusters correspond, in general, to the nonindustrialized municipalities and are far from the industrial core. The cluster in the south includes the municipalities of what is called the "Campanha" of Rio Grande do Sul and is usually considered to be the state's main regional problem. The northern cluster consists of the "Planalto" region. The clusters identified are roughly contiguous but not completely so. The spatially constrained implicit clustering does not, in fact, guarantee contiguity. For instance, Rio Grande and Pelotas, both situated in the south of the state, were included in the cluster of the industrial core. Although this also breaks with the spatial contiguity of the cluster, it makes economic sense. This area has an important industrial base, and the population of both municipalities (about 500,000 inhabitants) provides a sizeable market.

\section{MANUFACTURING WAGES IN RIO GRANDE DO SUL}

In this section, the impact of locational variables on manufacturing wages in Rio Grande do Sul is estimated by using a wage regression that considers the proxies calculated in the previous section. It is appropriate, however, to present an overview of the theories that have guided the econometric tests. 


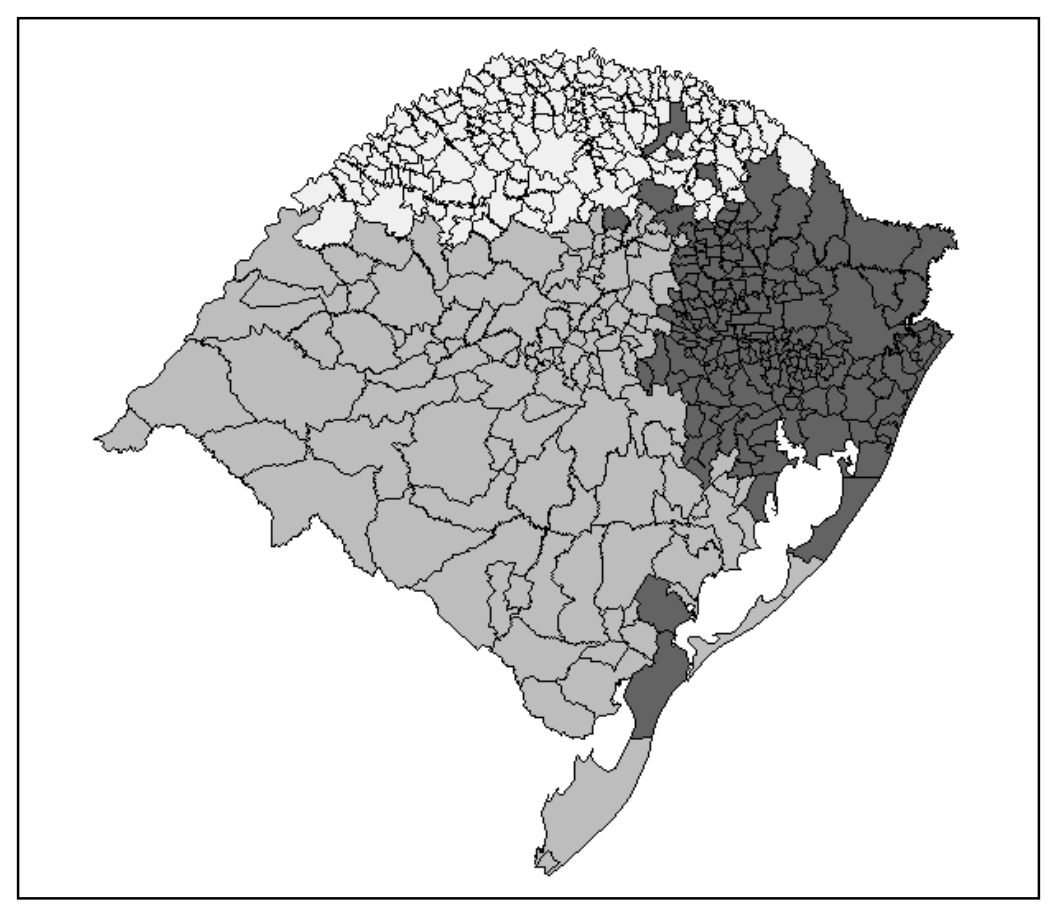

FIGURE 6. Implicit Clustering Regionalization $(k=3)$

\subsection{Theoretical Overview}

The main hypothesis is that locational externalities generate higher labor productivity and hence higher wages. Although this was a longstanding intuition, it was formalised and developed by New Economic Geography. Krugman, Fujita, Venables, and Thisse, for example, constructed models that explain the formation of a center-periphery distribution of economic activity. ${ }^{5}$ In the long run, and with the right parameters, nominal wages would be higher in the center and lower outside it. In other words, salaries would be positively related to market potential.

One of the criticisms that were made of NEG is that it was difficult to test its models. Many do not have unique equilibrium solutions and can only be solved by simulation or demand variables that are not easily available. However, this kind of criticism is no longer valid. Head and Mayer (2003) pointed out that there are a considerable number of empirical studies inspired by NEG. There are, of course, still many problems in the literature, one of which is how to be sure that the data cannot be explained by another

5 See Fujita and Thisse (2002) and Fujita, Venables, and Krugman (1999) for a unified presentation of NEG contributions. 
competing theory. ${ }^{6}$ Still, it is important to stress that NEG models, especially those related to the wage equation, have received substantial empirical support.

Gordon Hanson $(1997,1998)$ was one of the first economists to test an NEG model. His 1998 paper tests the Krugman (1991) model as developed by Thomas (1997). The model starts with two identical agents who consume two types of goods: manufactured goods and housing services. There is monopolistic competition, increasing returns on the production of manufactured goods, and iceberg transport costs. Adopting plausible parameters, production is concentrated in few locations.

Intuitively, agglomeration is a consequence of companies trying to reach local markets, reducing transport costs and minimising fixed costs. On the other hand, the centripetal forces are the competition near the center and higher wages (Hanson 1998). According to this approach, agglomeration economies make it possible to pay higher wages, which can be balanced against the higher costs of living, and/or losses in wellbeing, of living near industrial areas (Brakman, Garretsen, and van Marrweijk 2003, cap. $3)$.

Hanson (1998) modifies the Krugman (1991) model with the aim of estimating its structural parameters. Hanson's econometric regression, using data from continental USA counties, gives strong support to the predictions of the model: increasing returns on manufacturing together with higher wages near the economic center.

This paper does not perform a similar structural test of the Krugman (1991) model, since the lack of data makes it difficult to carry out a correct replication of Hanson's tests. In other words, the choice of variables and the research objectives were guided by Hanson's paper, but the results cannot be compared with his, nor understood in a structural way. Instead of using data from municipalities, an estimate will be made using individual census data. The research strategy is to estimate a wage regression (Mincer 1974) and include locational proxies. In formal terms:

$$
w_{i}=f\left(X_{i}, Y_{n}\right)
$$

where $w_{i}$ is the hourly wage of person $i$ in Brazilian Reais; $X_{i}=$ vector, including individual and occupational characteristics that may impact on the productivity of work or wages; and $Y_{n}$ is a vector with measurable locational aspects within the municipality where the individual $i$ works.

\footnotetext{
${ }^{6}$ Fingleton (2006) compares two non-nested models (NEG and Urban Economics) to explain local wage rates in Great Britain. In this case, the empirical test supports the Urban Economics model.
} 


\subsection{Variables and Sources}

Individual variables based on a sample of 10 percent of the total population of the 2000 Brazilian National Census (Instituto Brasileiro de Geografia e Estatística 2002) are as follows.

Dummies for schooling: number of years of study;

Dummies for age: measured in years;

Dummies for the colour of individuals: The criterion adopted mirrored the official one, i.e., self-identification of colour (yellow, white, native Brazilian, brown, and black) ${ }^{7}$

Dummy for gender;

Dummies for occupation: three-digit index based on the Brazilian Classification of Occupations $(\mathrm{CBO}) .^{8}$

Locational Variables:

Agglomeration (smoothed): see Section 2.1;

Market Potential: see Section 2.3;

Regional Custers: see Section 2.4;

Urbanization Rte: share of the population of a municipality living in urban areas in 2000 (Source: Programa das Nações Unidas para o Desenvolvimento 2003);

Urban Population: total population living in urban areas in 2000 (Source: Programa das Nações Unidas para o Desenvolvimento 2003).

\subsection{Estimation and Results}

The selected sample from the Census data for Rio Grande do Sul considers manufacturing workers in formal employment who are literate and between 18 and 65 years old. The use of this criterion reduced the sample to exactly 54,862 individuals. The strategy of the analysis was to include all the demographic and occupational data available as explanatory variables in the Mincerian regression.

The data bank with the municipal data of the first section of the study was merged with the individual data relating to the place of work, not the place of residence. All regressions were carried out using R 2.4.0 (R Development Core Team 2006) and ordinary least squares and, whenever it made sense, all variables were transformed according to their natural logarithm.

\footnotetext{
${ }^{7}$ Although it may sound politically incorrect to use colours to express ethnic features, these categories are officially adopted by the Brazilian Federal Statistical Institute (IBGE). Ethnic relations and definitions are especially complex in Brazil. In fact, more than 70 percent of selfidentified white Brazilian males have at least 10 percent of genes of African origin (Pena and Bortolini 2004, p. 43).

${ }^{8}$ Muendler (2006) provides definitions and converters between the $\mathrm{CBO}$ and the International classification system (ISCO-88).
} 
Model I is just a benchmark, but it supports the hypothesis concerning gender and racial discrimination in the job market. Women's wages are about 23 percent lower than men's, and black or brown individuals receive 10 percent and 6 perent lower wages than white individuals respectively, controlling for age, schooling and occupation. Obviously, the results may also be influenced by non-observable parameters, for instance, different levels in the quality of education available to each group.

Model II adds locational variables to Model I. Even when controlled for individual traits, wages are higher in locations with higher market potential, i.e., in industrialized

\section{TABLE 1}

Regression Coefficients

Dependent variable: LN (wage per hour in main occupation)

\begin{tabular}{|c|c|c|c|}
\hline Variable & $\mathrm{I}$ & II & IIII \\
\hline \multirow[t]{2}{*}{ Constant } & $1.458^{* * *}$ & $-1.792^{* *}$ & $-1.752^{* *}$ \\
\hline & $(11.51)$ & $(-11.86)$ & $(-11.91)$ \\
\hline \multirow[t]{2}{*}{ Woman } & $-0.259^{* *} *$ & $-0.261^{* * *}$ & $-0.261^{* * *}$ \\
\hline & $(-55.11)$ & $(-57.58)$ & $(-57.67)$ \\
\hline \multirow[t]{2}{*}{ Black } & $-0.101^{* * *}$ & $-0.115^{* * *}$ & $-0.114^{* * *}$ \\
\hline & $(-10.78)$ & $(-12.65)$ & $(-12.70)$ \\
\hline \multirow[t]{2}{*}{ Yellow } & -0.026 & -0.026 & -0.025 \\
\hline & $(-1.06)$ & $(-0.40)$ & $(-0.39)$ \\
\hline \multirow[t]{2}{*}{ Brown } & $-0.058^{* * *}$ & $-0.058^{* * *}$ & $-0.058^{* * *}$ \\
\hline & $(-7.09)$ & $(-7.471)$ & $(-7.45)$ \\
\hline \multirow[t]{2}{*}{ Native Brazilian } & -0.018 & -0.037 & -0.038 \\
\hline & $(-0.43)$ & $(-0.958)$ & $(-0.97)$ \\
\hline \multirow[t]{2}{*}{ Market Potential } & & $0.161^{* * *}$ & $0.158^{* * *}$ \\
\hline & & $(29.12)$ & $(31.27)$ \\
\hline \multirow{2}{*}{ Agglomeration (smoothed) } & & $0.725^{* * *}$ & $0.704^{* * *}$ \\
\hline & & $(13.44)$ & $(13.84)$ \\
\hline \multirow[t]{2}{*}{ Campanha } & & $-0.058^{* * *}$ & $-0.051^{* * *}$ \\
\hline & & $(-5.40)$ & $(-5.678)$ \\
\hline \multirow[t]{2}{*}{ Planalto } & & -0.011 & \\
\hline & & $(-1.15)$ & \\
\hline \multirow[t]{2}{*}{ Urbanization Rate } & & $0.122^{* * *}$ & $0.121^{* * *}$ \\
\hline & & $(11.42)$ & (11.36) \\
\hline \multirow[t]{2}{*}{ Urban Population } & & $-0.025^{* * *}$ & $-0.025^{* * *}$ \\
\hline & & $(-8.16)$ & $(-8.08)$ \\
\hline $\mathrm{R}^{2}$ & 0.527 & 0.563 & 0.563 \\
\hline F value & 306 & 344 & 346 \\
\hline \multicolumn{4}{|c|}{$\begin{array}{l}\text { Note: } t \text { values in parentheses: }{ }^{*} \text { significant at } 0.05 ;{ }^{* *} \text { significant at } 0.01{ }^{* * *} \text { significant a } \\
\text { less than } 0.001 . \\
137 \text { dummies for } 3 \text {-digit occupation omitted. Estimated values for age and schooling } \\
\text { dummies are presented in Figures A. } 3 \text { and A. } 4 \text { of the Appendix. }\end{array}$} \\
\hline
\end{tabular}


and more urbanized clusters. All estimators for variables aimed to represent these dimensions have the features expected and were statistically significant at less than 0.1 percent. It is interesting to note that the coefficient related to the population of the municipality is negative. This suggests that the (small) diseconomies of agglomeration show up when there are controls for the other locational variables. In Model III, the non-significant variable (Planalto) was removed. The results were very similar to the previous model, with no major changes in the values of the estimators.

Based on the results of Model III, working in a municipality located in the Campanha cluster reduces wages by 5 percent. The estimated coefficients indicate that the marginal effect of an increase of 1 percent in the market potential or in the agglomeration was estimated to generate an increase of 0.16 percent and 0.70 percent in wages, respectively. A hypothetical increase of 1 percent in the urbanization rate of the municipality is related to an increase of 0.12 percent in individual salaries, whereas the same increase in the urban population would lead to a slight -0.03 percent fall in wages.

It is important to stress that the results refer to nominal and not to real wages. As indicated above, one of the conditions of equilibrium of the model is that there are no differences in real wages among similar individuals. ${ }^{9}$

\section{FINAL REMARKS}

In this paper, we aimed to test the effects of the locational dimension on manufacturing wages in present-day Rio Grande do Sul. Several analytical techniques were used to highlight the spatial patterns of the distribution of industrial activity in the state. We showed how clustered this sector is and estimated the market potential of each municipality.

Regression analysis using individual census data suggested that "space matters" in terms of the wages of workers. The results support the hypothesis of New Economic Geography, which asserts that nominal wages, with the proper controls, would be lower in places with lower market potential, low urbanization, low agglomeration economies, and far from the economically dynamic regions of the state.

One of the contributions we try to make in this paper is to show the usefulness of merging spatial data and individual data in the study of issues concerning regional economics. This has made it possible to estimate the role of agglomeration, urbanization economies, and market potential on the wages of manufacturing workers. Nevertheless, it is necessary to exercise caution when interpreting the results. Hanson (2000) drew atten-

\footnotetext{
${ }^{9}$ Miranda et al. (2002) ran Mincerian regressions for individuals using another data source and using dummy variables for the southeastern and northeastern regions of Brazil. They found that it would be necessary to establish a price index 60 percent higher in the southeast in order to equalize real wages between the regions. The authors took this result as an indication of regional differences in Brazil and did not make any reference to New Economic Geography models.
} 
tion to the problems concerning agglomeration economies and their effects. There may be unobserved exogenous local variables that make it difficult to understand precisely how agglomeration economies work. Moreover, the present results give support not only to NEG but to other theoretical approaches. Further empirical research on the location and characteristics of Rio Grande do Sul firms will hopefully identify the sources of agglomerations economies and suggest the suitable theoretical model. ${ }^{10}$

\section{REFERENCES}

Anselin, L., 1995. "Local Indicators of Spatial Association - LISA," Geographical Analysis 27(2), 93-115. , 1998. "Exploratory Spatial Data Analysis in a Geocomputational Environment," in P. Longle, S. Brooks, R. McDonnell, and W. Macmillan (eds.), Geocomputation: A Primer. Wiley and Sons: New York. , 2004. Geoda: Geodata Analysis Software. University of Illinois.

Alonso, J., M. Benetti, and P. Bandeira, eds., 1994. Crescimento Econômico da Região Sul no Rio Grande do Sul: Causas e Perspectivas. Fundação de Economia e Estatística Siegfried Emanuel Heuser: Porto Alegre, Brazil.

Bivand, R., 2006. "Implementing spatial data analysis software tools in R," Geographical Analysis 38(1), 23-40.

Brakman, S., H. Garretsen, and C. van Marrewijk, 2003. An Introduction to Geographical Economics. Cambridge University: Cambridge.

Duque, J.C. and J.S. Raúl-Ramos, 2006. "Supervised Regionalization Methods: A Survey," Research Institute of Applied Economics 2006/8: Barcelona, Spain.

Duranton, G. and H.G. Overman, 2005. "Testing for Localisation using MicroGeographic Data," Review of Economic Studies 72 (4), 1077-1106.

Fingleton, B., 2006. "The New Economic Geography versus Urban Economics: An Evaluation Using Local Wage Rates in Great Britain," Oxford Economic Papers 58 (3), 501-530.

Fundação de Economia e Estatística (FEE), 2003. PIB Municipal do RS - 1985-01. CDROM. FEE: Porto Alegre, Brazil.

, 2006. FEEDADOS. Available at http://www.fee.rs.gov.br/sitefee/pt/content/ estatisticas/pg feedados.php. December.

Fujita, M. and J.F. Thisse, 2002. Economics of Agglomeration: Cities, Industrial Location, and Regional Growth. Cambridge, MA: Cambridge University Press.

Fujita, M., A.J. Venables, and P. Krugman, 1999. The Spatial Economy: Cities, Regions, and International Trade. Cambridge, MA: MIT University Press.

Gonzales, R.H., J. L. T. Silva, L. F. Neves Jr., L H Paiva, M. M. Antunes, 2002. A Informalidade no Mercado de Trabalho Brasileiro e as Políticas Públicas do Governo Federal. MTE: Brasília, Brazil.

\footnotetext{
${ }^{10}$ The contributions of Rosenthal and Strange (2001) and Duranton and Overman (2005) could be replicated and shed new light on the Rio Grande do Sul regional issues.
} 
Hanson, G., 1997. "Increasing Returns, Trade and the Regional Structure of Wages," Economic Journal 107(440), 113-33.

, 1998. "Market Potential, Increasing Returns, and Geographic Concentration," National Bureau of Economic Research Working Paper 6429: Cambridge, MA.

, 2000. "Scale Economies and the Geographic Concentration of Industry," National Bureau of Economic Research Working Paper 8013: Cambridge, MA.

Harris, C., 1954. "The Market as Factor of Localization of the Industry in the United States," Annals of the Association of American Geographers 39(4), 315-348.

Head, K. and T. Mayer, 2004. "The Empirics of Agglomeration and Trade," J.V. Henderson and J.F. Thisse (eds.), Handbook of Regional and Urban Economics. Elsevier: London.

Instituto Brasileiro de Geografia e Estatística (IBGE), 2002. Censo Demográfico 2000: Microdados da Amostra - RS - $2^{\mathrm{a}}$ edição. CD-ROM. IBGE: Brasília, Brazil.

Krugman, P., 1991. "Increasing Returns and Economic Geography," Journal of Political Economy 99(3), 483-499.

Lautert, V., 2004. "A Dinâmica da Concentração Geográfica na Indústria do Rio Grande do Sul (1872-2000)," II Encontro de Economia Gaúcha Conference Papers, Fundação de Economia e Estatística: Porto Alegre, Brazil.

Mincer, J., 1974. Schooling, Experience and Learning. Columbia University: New York.

Miranda, R., C. Oliveira, M. Almeida, M. MacDowell, R. Ellery Jr., and N. Zackseski, 2002. "Regional Wage Differences in Brazil: Is There a Regional Problem?" II Encontro Brasileiro de Estudos Regionais e Urbanos Conference Papers, ABER: São Paulo, Brazil.

Muendler, M., 2006. Available at: http://www.econ.ucsd.edu/muendler/html/brazil.html, December.

O'Sullivan, D. and D.J. Unwin, 2003. Geographic Information Analysis. Wiley: Hoboken, NJ.

Pena, S. and M.C. Bortolini, 2004. "Pode a Genética Definir Quem Deve se Beneficiar das Cotas Universitárias e demais Ações Afirmativas?" Estudos Avançados 18(50), $31-50$.

Programa das Nações Unidas para o Desenvolvimento (PNUD), 2003. Atlas do Desenvolvimento Humano no Brasil. CD-Rom. PNUD: Brasília, Brazil.

R Development Core Team, 2006. Available at: http://www.R-project.org.

Rosenthal, S. and W.C. Strange, 2001. "The Determinants of Agglomeration," Journal of Urban Economics 50 (2), 191-229.

Ruiz, R.M. and E.P. Domingues, 2005. "Corredores Industriais na Região Sul," VIII Encontro de Economia da Região Sul Conference Papers. ANPEC/Sul: Porto Alegre, Brazil.

Thomas, A., 1997. "Increasing Returns, Congestion Costs and the Geographic Concentration of Firms.” International Monetary Fund: Washington, D.C. 


\section{APPENDIX}

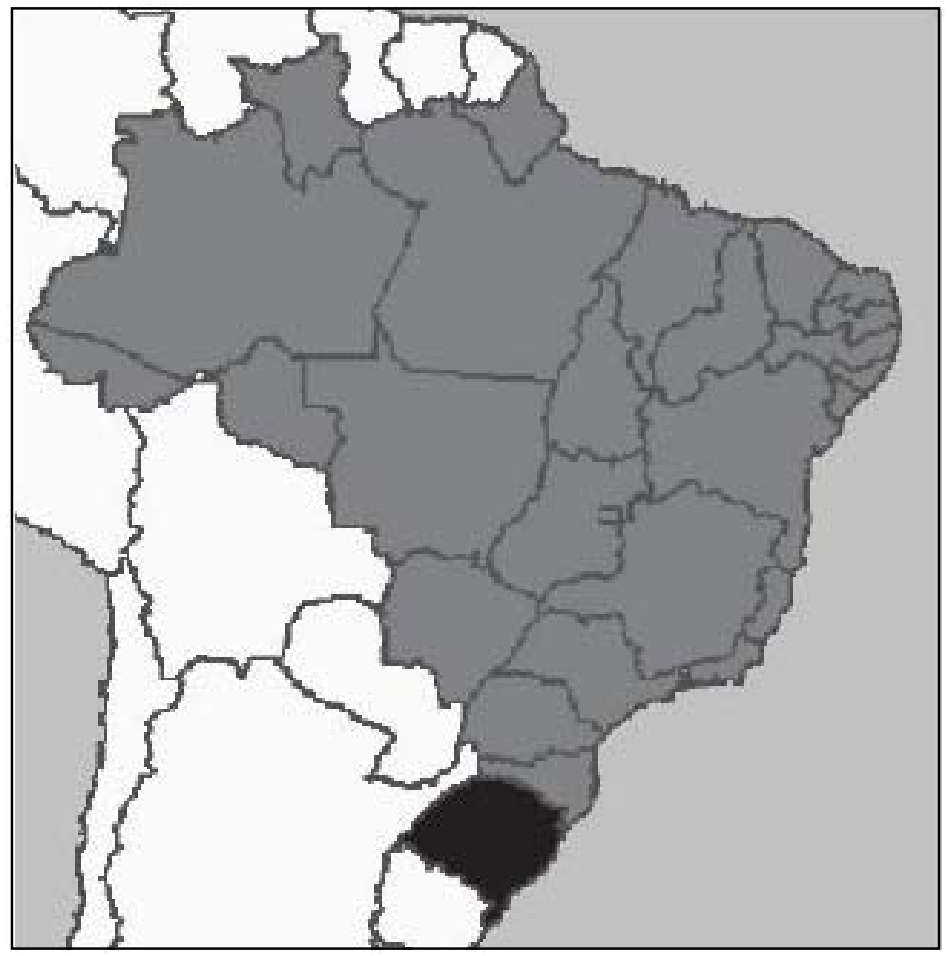

FIGURE A.1. Brazil and Rio Grande do Sul 


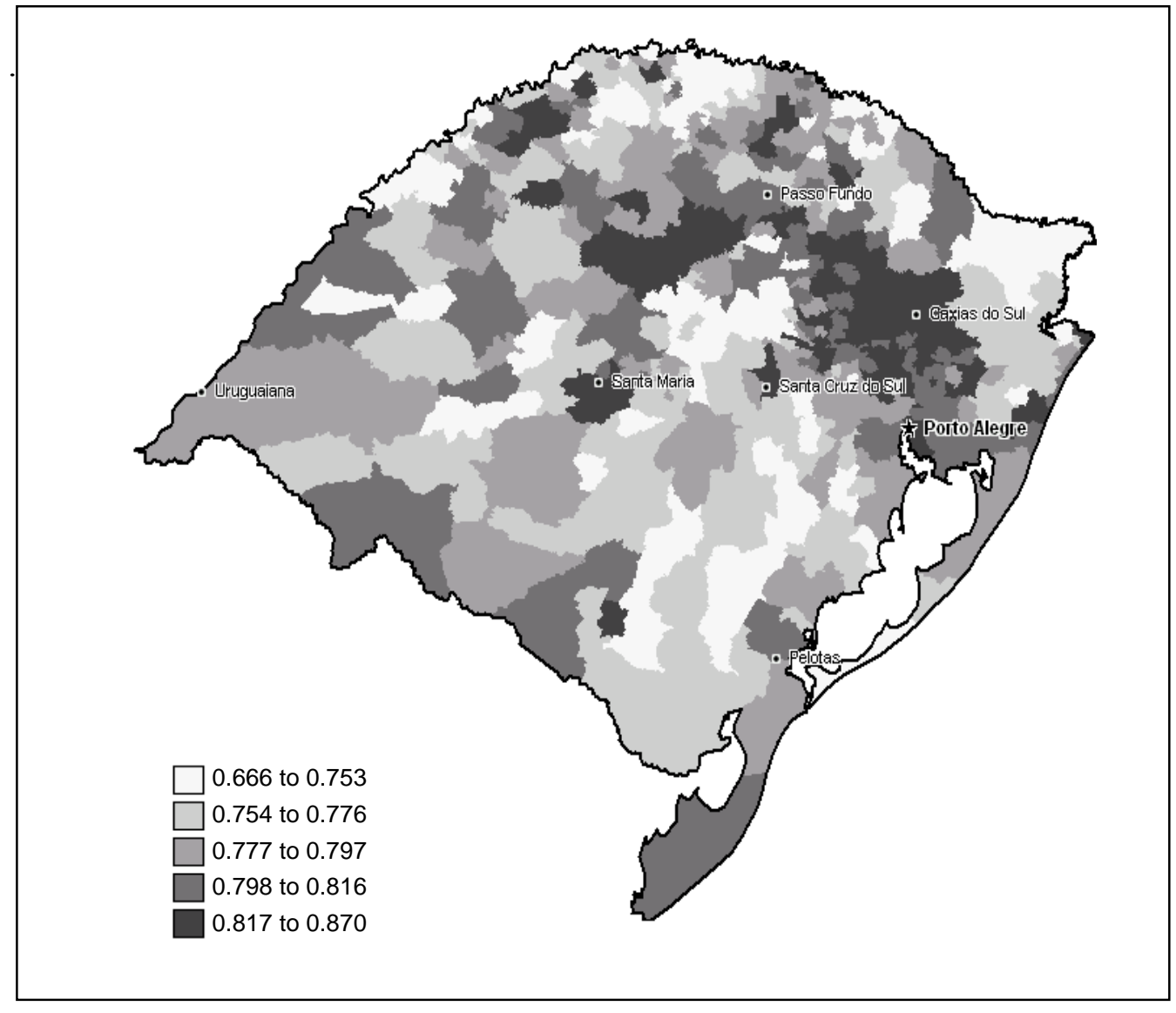

FIGURE A.2. Human Development Index, Rio Grande d Sul -2000 SOURCE: PNUD (2003) 
The Review of Regional Studies, Vol. 36, No. 3, 2006, pp. 304-323

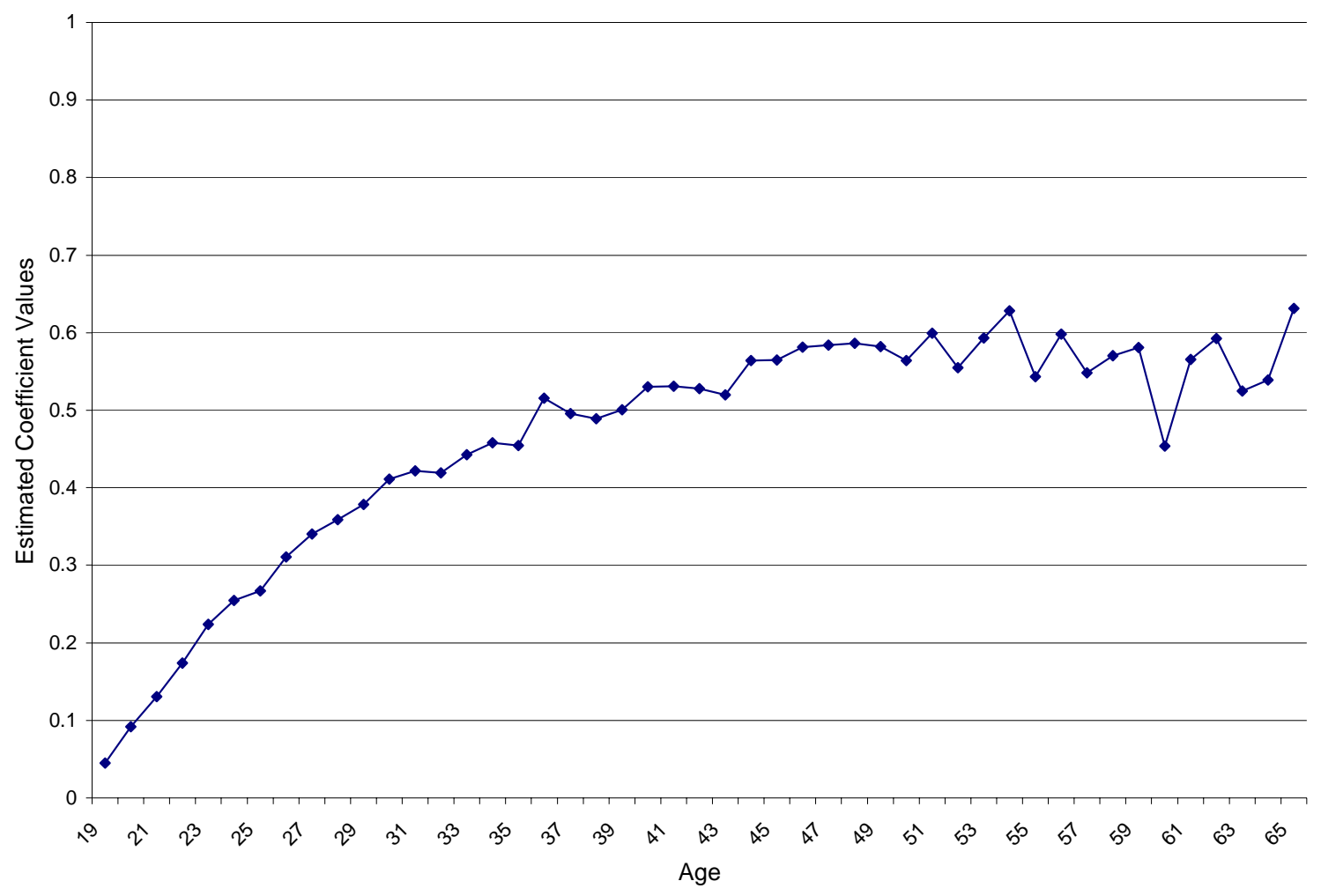

FIGURE A.3. Estimated Coefficient Values for the Age Dummy Variables

NOTE: Estimated values were taken from the Model III. See Section 3 of the paper for details. All coefficients were significant at 0.1 percent. 


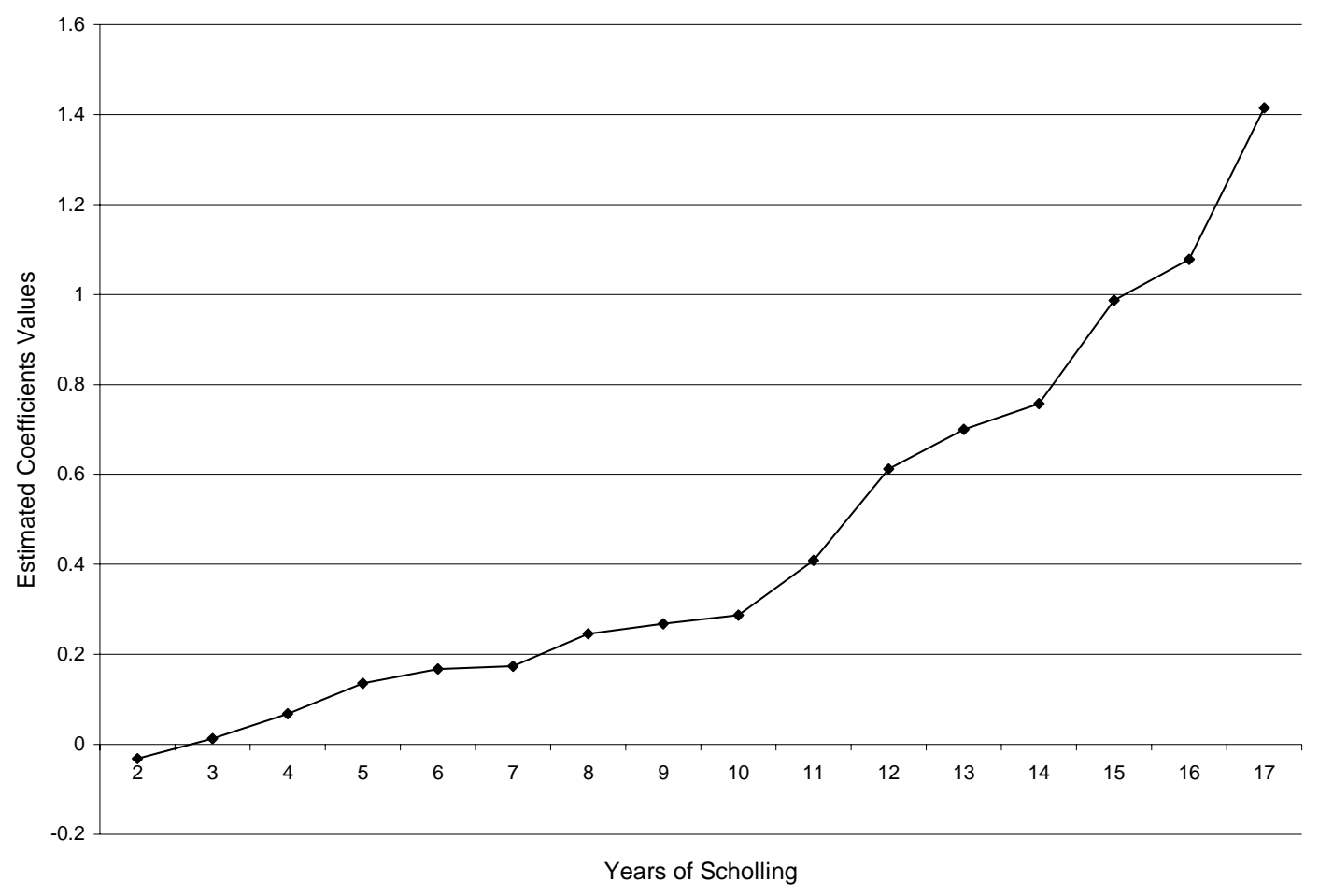

FIGURE A.4. Estimated Coefficient Values for the Schooling Dummy Variables

NOTE: Estimated values were taken from the Model III. See section 3 of the paper for details. All coefficients were significant at 0.1 percent, except for 2 and 3 years of schooling. 